Leading Article

\title{
Aetiology and pathogenesis of ulcerative colitis and Crohn's disease
}

\author{
D.P. Jewell
}

Gastroenterology Unit, The Radcliffe Infirmary, Oxford OX2 6HE, UK.

Ulcerative colitis and Crohn's disease continue to baffle us with regard to their aetiology and pathogenesis. Indeed, our understanding has increased little since the early days of ulcerative colitis when the major debate concerned the role of the intestinal flora and the host's response to it. It seems well established that the familial incidence is about $10-15 \%$ and recent studies from Sweden, in twins, have suggested that the genetic factor may operate more strongly for Crohn's disease. ${ }^{1}$ However, this genetic susceptibility cannot be described in terms of HLA associations which, at best, are exceptionally weak. $^{2}$

It seems likely that each disease represents a complex interplay between genetic and environmental factors, although the latter are as poorly understood as the former. Recently, the isolation of an atypical mycobacterium from Crohn's tissue has stimulated interest in an infective aetiology. ${ }^{3}$ The organism appears identical to $M$. paratuberculosis, the causative organism of Johne's disease in farm animals, and has been isolated in the USA and Europe. However, it can only be isolated from a minority of patients: specificity for Crohn's disease is not yet proven, and antimycobacterial therapy is not universally effective. For ulcerative colitis, no specific pathogen is currently suspected although recent reports that the Escherichia coli of the colonic flora of patients may express 'adhesins'4 are of interest since this would enable the bacteria to attach themselves to the colonic epithelial cells. This could lead to impaired epithelial function and/or enable access into the mucosa by the bacteria. Other environmental factors which have been implicated include diet, smoking, and oral contraceptives. The good clinical response of active colonic Crohn's disease to either an elemental $\operatorname{diet}^{5}$ or faecal diversion ${ }^{6}$ suggests that dietary components may be important. However, the lack of effect on the course of Crohn's disease by dietary modification largely negates any role for sugar or fibre. ${ }^{7,8}$ The association between

Correspondence: D.P. Jewell M.A., D.Phil., F.R.C.P.

Received: 16 May 1989 non-smoking and ulcerative colitis, and smoking with Crohn's disease, has been consistently reported ${ }^{9.10}$ but defies explanation. The rather weak association between either disease in young women and oral contraceptive usage is also unexplained. ${ }^{9}$ The potential effects of smoking or oral contraceptives on mucus production, arachidonate metabolism, blood flow, or epithelial integrity would be well worth studying.

The possibility that Crohn's disease represents a diffuse disorder affecting the whole of the gastrointestinal tract has been suggested by both physiological and immunological studies of intestine apparently uninvolved with the disease. This concepto has received further support by the observation that small intestinal permeability is increased not only inco patients but in their first degree relatives. ${ }^{\text {" This leads. }}$ to the interesting hypothesis that the genetic susceptibility might be expressed as abnormal epithelial cell function. The reduced metabolism of short chain fatty acids by isolated colonic epithelial cells from patients with ulcerative colitis in remission ${ }^{12}$ and the observation that mucus synthesis in these patients may be abnormal ${ }^{13}$ provide further evidence that the epithelial cell may not be normal even when the disease is in histological remission.

Immunological studies have failed to provide convincing evidence for a major immune defect in the mucosal immune system. ${ }^{14}$ Recent observations have shown that, although local IgG synthesis increases considerably in both diseases, the major increase in ulcerative colitis is in the IgGl subclass, whereas Crohn's disease is mainly associated with an increase in IgG2 synthesis. ${ }^{15,16}$ Since the subclass response is dependent upon the nature of the antigen (protein, carbohydrate or bacterial), this is the first indication that the stimulus to the local immune response may differ in two diseases. Changes in the macrophage populations of the mucosa, which are not shared by infectious causes of colitis, also point to specific factors initiating inflammation. ${ }^{17}$

The pathogenesis of the extra-intestinal manifestations is equally obscure. Patients who possess the phenotype HLA-B27 or HLA-DR3 are susceptible to 
ankylosing spondylitis or primary sclerosing cholangitis respectively. Whether this relates to crossreactivity or 'molecular mimicry' between HLA and bacterial antigens is far from clear but it is noteworthy that the majority of patients with sclerosing cholangitis have circulating antibodies to colonic epithelial cells which are known to cross-react with bacterial lipopolysaccharides. ${ }^{18}$ Erythema nodosum, acute uveitis, and the acute polyarthropathy may be related to circulating immune complexes, ${ }^{19}$ but not all investigators have confirmed this finding.

Arteritis is rare but cases of polyarteritis nodosa associated with Crohn's disease have been reported ${ }^{20}$ and patients are also described with large vessel arteritis. In this issue, there are further reports of an

\section{References}

1. Tysk, C., Lindberg, E., Jarnerot, G. \& FloderusMyrhed, B. Ulcerative colitis and Crohn's disease in an unselected population of monozygotic and dizygotic twins. A study of heritability and the influence of smoking. Gut 1988, 29: 990-996.

2. Biemond, I., Burnham, W.R., D'Amaro, J. \& Langman, M.J.S. HLA-A and B antigens in inflammatory bowel disease. Gut 1986, 27: 934-941.

3. Hampson, S.J., McFadden, J.J. \& Hermon-Taylor, J. Mycobacteria and Crohn's disease. Gut 1988, 29: 1017-1019.

4. Burke, D.A., Axon, A.T.R. Adhesive E. coli in inflammatory bowel disease and infective diarrhoea. $\mathrm{Br}$ Med J 1988, 297:102-104.

5. O'Morain, C., Segal, A.W. \& Levi, A.J. Elemental diet as primary treatment of acute Crohn's disease: a controlled diet. Br Med J 1984, 288: 1859-1862.

6. Harper, P.H., Lee, E.C.G., Kettlewell, M.G.W., Bennett, M.K. \& Jewell, D.P. Role of the faecal stream in the maintenance of Crohn's colitis. Gut 1985, 26: 279-284.

7. Ritchie, J.K., Wadsworth, J., Lennard-Jones, J.E. \& Rogers, E. Controlled multicentre therapeutic trial of an unrefined carbohydrate, fibre-rich diet in Crohn's disease. Br Med J 1986, 295: 517-520.

8. Levenstein, S., Prantera, C., Luzi, C. \& D'Ubaldi, A. Low residue or normal diet in Crohn's disease: a prospective controlled study in Italian patients. Gut 1985, 26: 989-993.

9. Vessey, M.P., Jewell, D.P., Smith, A., Yeates, A. \& McPherson, K. Chronic inflammatory bowel disease, cigarette smoking, and use of oral contraceptives: findings in a large cohort study of women of childbearing age. $\mathrm{Br}$ Med J 1986, 292: 1101-1103.

10. Lindberg, E., Tysk, C., Andersson, K. \& Jarnerot, G. Smoking and inflammatory bowel disease. A case control study. Gut 1988, 29: 352-357.

11. Hollander, D., Vadheim, C.M., Brettholz, E., Peterson, G.M., Delahaunty, T. \& Rotter, J.I. Increased intestinal permeability in patients with Crohn's disease and their relatives. Ann Intern Med 1987, 105: 883-885.

12. Roediger, W.E.W. The colonic epithelium in ulcerative colitis: an energy-deficient disease? Lancet 1980, ii: $712-715$. arteritis occurring which resembles Takayasu's disease. $^{21,22}$ This complication is rare but is now sufficiently well reported to make a chance association unlikely. Immune complex deposition has been postulated as one possible mechanism but the presence of immune complexes has not been demonstrated. Other potential mechanisms include damage to endothelial cells with the subsequent development of a vasculitic process. Increased circulating concentrations of cytokines, especially interleukin $1,{ }^{23}$ or the products of arachidonate metabolism may be responsible for such damage and both are known to be increased in patients with active inflammatory bowel disease. As with the pathogenesis of the mucosal inflammation itself, hypotheses abound but few hard facts exist.

13. Podolsky, D. \& Isselbacher, K.J. Glycoprotein composition of colonic mucosa. Gastroenterology 1984, 87: 991-998.

14. Elson, C.O. The immunology of inflammatory bowel disease. In: Kirsner, J.B. \& Shorter, R.G. (eds) Inflammatory Bowel Disease, 3rd Edition. Lea and Febiger Philadelphia, 1988, pp. 97-164.

15. Scott, M.G., Nahm, M.H., Macke, K., Nash, G.S Bertovich, M.J. \& MacDermott, R.P. Spontaneou \& secretion of IgG subclasses by intestinal mononucleaf cells: differences between ulcerative colitis, Crohn's disease and controls. Clin Exp Immunol 1986, 66 209-215.

16. Kett, K., Rognum, T.O. \& Brandtzaeg, P. Mucosal subclass distribution of immunoglobulin G-producing cells is different in ulcerative colitis and Crohn's disease of the colon. Gastroenterology 1987, 93: 919-924.

17. Mahida, Y.R., Gionchetti, P., Vaux, D., Patel, S. \& Jewell, D.P. Macrophage subpopulations in lamina propria of normal and inflamed colon and terminal ileum. Gut 1989, 30: 826-834.

18. Chapman, R.W., Cottone, M., Selby, W.S., Shepherd, H.A., Sherlock, S. \& Jewell, D.P. Serum autoantibodies, ulcerative colitis and primary sclerosing cholangitis. Gut 1986, 27: 86-91.

19. Hodgson, H.J.F., Potter, B.J. \& Jewell, D.P. Immune complexes in ulcerative colitis and Crohn's disease. Clin Exp Immunol 1977, 29:187-196.

20. Dyer, N.H., Dawson, A.M., Berbor, J.L., Borrie, P.F. \& Stansfield, A.G. Cutaneous polyarteritis nodosa associated with Crohn's disease. Lancet 1970, i, $648-650$.

21. Ikenaga, H., Ogihara, T., Kou, S. et al. Does a common pathophysiological basis exist in the association of ulcerative colitis and Takayasu's aortitis? Report of a case. Postgrad Med J 1989 65: 761-764.

22. Sheehan-Dare, R.A., Goodfield, M.J.D., Wilson, P.D. \& Rowell, N.R. Axillary artery occlusion as a presenting feature of Crohn's disease. Postgrad Med J 1989, 65: 758-760.

23. Dinarello, C. Interleukin 1. Dig Dis Sci 1988, 33: 25-35.

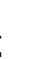

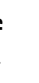
$\overrightarrow{0}$

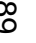

